\title{
Multilevel converter integration for low voltage ride through controlling renewable wind energy conversion systems
}

\author{
Mahrous Ahmed*,*, Bassem Alamri*, Mohamed Metwally*, Mosleh Alharthi*, Ali Alzaed**, Nagy \\ Elkalashy*, Farhan Salem*, Saad Mekhilef****, Mohamed Orabi*** and Sherif Ghoneim* \\ *Electrical Engineering Department, College of Engineering, Taif University, Taif 21944, Saudi Arabia \\ **Architectural Eng. Dept., College of Engineering, Taif University, Taif 21944, Saudi Arabia \\ ***APEARC, Faculty of Engineering, Aswan University, 81542, Aswan, Egypt \\ ****Department of Electrical Engineering, University of Malaya, Kuala Lumpur, Malaysia \\ *Corresponding Author: m.elsamman@tu.edu.sa
}

Submitted: $15 / 02 / 2020$

Revised: $\quad 30 / 12 / 2020$

Accepted: 31/01/2021

\begin{abstract}
In this study, a new control of grid-connected doubly-fed induction generators (DFIGs) is introduced to attain lowvoltage ride-through capability. The grid-side converter is proposed to be a multilevel converter (MLC) controlled by conventional DC-link voltage controller. The MLC is designed and integrated into the grid-connected DFIG. The rotor-side converter is considered a two-level conventional converter controlled by the proposed virtual voltage strategy. The virtual strategy is to use the designed input control signal rather than the actual measured one during system disturbance. The system disturbance in this study is the voltage dip. The proposed virtual controller is designed to use busbar voltage during normal operation, whereas it utilizes the designed virtual voltage during wide range conditions of low grid voltages. The energy conversion system currents are increased due to voltage dip disturbances. The use of designed virtual voltage values is proposed as inputs to the controller to limit these currents at the rating values. These virtual voltages are extracted using direct-quadrature machine representation and fixed machine currents at the rated values or lower. On the basis of the proposed control concerning the virtual voltage concept, the generator currents are limited to the rated values, thereby protecting the energy conversion system during low grid voltages. Simulation results prove the validity of the proposed control scheme during extreme low voltages.
\end{abstract}

Keywords: Doubly-Fed Induction Generator (DFIG); Renewable Wind Turbine; Low-Voltage Ride-Through (LVRT); Multilevel Converter (MLC); Virtual Voltage.

\section{INTRODUCTION}

Doubly-fed induction generators (DFIGs) have attracted attention for wind turbines in renewable energy applications. The connection of DFIGs to national grids has increased because of their merits with respect to permanent magnet synchronous generators (Seman et al., 2006). DFIG wind energy conversion systems do not require much power converter capacity, can easily regulate active and reactive powers, due to the utilization of two parallel paths from the stator and rotor directions, and are independent of permanent magnets (Lei et al., 2013). The performance and analysis of wind energy conversion systems utilizing DFIGs have been presented in different studies published on modeling (Lei et al., 2013), designing (You et al., 2012), and analyzing the issues of unbalanced operations (Hu et al., 2009). In Ahmed et al. (2019), the conventional two-level inverter was replaced with a multilevel converter (MLC). The MLC 
was integrated with a DFIG. The performance of the system was investigated during transient ground faults. The MLC improved the performance of the DFIG control system during single-phase auto-recloser operation. However, the single-phase auto-recloser provided a small stress on the DFIG because it was implemented in the double-circuit transmission system connected between the wind farm and the power network. Further study is required for threephase faults that can be represented by different voltage dip disturbances.

The dynamic performance of grid-connected DFIGs has arisen due to a wide increase in wind energy in electrical power networks (Qiao et al., 2008). Therefore, a grid-connected wind turbine behaves like a normal power plant and feeds the network during normal and abnormal network conditions. Hence, many countries have developed certain grid-operating codes and have enhanced their grids with wind turbine energy. In the area of power and energy, power engineers should pay special attention to two main issues (FERC, 2005; Qiao et al., 2008). The first issue is the operation control during normal operating conditions, where active and reactive power control occurs. The second issue is the operation control during grid-fault disturbances, where low-voltage ride-through (LVRT) capability is possible. In Alsmadi et al. (2018), the performance improvement of the dynamic behavior of grid-connected DFIG under LVRT conditions was investigated in detail. However, only the common design of DFIGs was considered. In this study, the effective performance of the novel ride-through capability strategy was compared with traditional control schemes.

The LVRT capability of DFIGs is designed to enhance the DFIG during the highly subjected grid faults either far or close faults to DFIG (Rashid et al., 2015). However, a direct coupling occurs between the generator stator and grid and the rotor connected to the grid through two back-to-back converters. They are the rotor-side converter (RSC) and grid-side converter (GSC) (Muller et al., 2002). During low grid voltages, the voltage of the DC-link between the two converters intensely increases, thereby leading to damage. The wind turbine energy system must ride through during grid faults to overcome damage to the DFIGs. The modified control of the superconducting coil and RSC-based superconducting magnetic energy storage fault current limiter protection schemes were investigated in Xiao et al. (2018).

LVRT enhancement methods can be subdivided into two parts: hardware development or enhancement using the control. Crowbar and chopper concepts are the two main hardware schemes that can divert the rotor overcurrent and the DC-link overvoltage (Abad et al., 2011; Tohidi et al., 2013; Vidal et al., 2013). The enhancement of fault ride through (FRT) capabilities of a DFIG-based dynamic voltage restorer (DVR) integrated with feed-forward and feedback control was investigated in Amalorpavaraj et al. (2017). However, using a DVR increases the hardware elements in the overall system, including the coupling transformer, filter, voltage source converter, and DC source. The second LVRT enhancement methods are smart and less expensive, but the performance of the DFIG is limited by the RSC capacity during grid-voltage sags (Zou et al., 2016). Therefore, studies supporting control-based LVRT capability should be continued. In Uddin et al. (2018) and Li et al. (2018), the control-based LVRT capability of DFIGs was presented on the basis of a hybrid scheme, a time domain analysis, and an amplitude/phase angle control of flux. In El-Naggar et al. (2017), a peak short circuit current was reduced in the LVRT to utilize the rotor voltage. However, MLCs are rarely used in DFIG systems.

MLCs (Colak et al., 2011; Hasan et al., 2014; Debnath et al., 2015; Eduganti et al., 2015, Zhang et al., 2017; Lu et al., 2017) have some well-known attractive advantages that make them more frequently used compared with conventional two-level H-bridge converters. These advantages are the capability of processing high power, synthesizing high output voltage levels, turning on/off at a low-switching frequency, improving output voltage waveforms with increasing voltage levels, and having low stresses on their switches. Most MLCs are modular, indicating that their structures consist of similar and repeated units. Therefore, they have high-operation immunity during faults in which they can continue to operate by using a modified control algorithm.

Cascaded H-bridge (CHB) converters (Mokhberdoran et al., 2014; Muñoz et al., 2015; Gadalla et al., 2017; Noman et al., 2017; Sheir et al., 2019) are one of the main structures of MLCs. From the point of view of DC batteries used, CHB converters can be divided into two categories: symmetric and asymmetric for equal and unequal 
DC sources, respectively. The use of symmetric or asymmetric (Mokhberdoran et al., 2014; Sheir et al., 2019) is a trade-off between generating lower voltage levels at equal switch ratings or generating higher voltage levels at different switch ratings. Hybrid MLCs (Hasan et al., 2014; Lu et al., 2017) are another circuit configuration technique, where similar and dissimilar circuits can be used and designed on the basis of the application.

In this study, the integration of MLCs at the grid side within DFIGs is introduced. The LVRT capability in DFIG-based wind turbines is enhanced using the proposed virtual voltage control to safely keep the grid connection at a wide range of grid-voltage dips. The merits of using this combined control are demonstrated on a MATLAB/ Simulink environment-based simulation using six 1.5-MW DFIG-based wind turbines connected to the power grid. The transient and steady-state waveforms of three-phase rotor currents, active power, and reactive power are presented to evaluate the proposed control method during extreme low voltages caused by faults. The rest of this paper is arranged as follows. First, the proposed virtual voltage control integration with LVRT is given in detail. Second, the incorporation of MLCs with the proposed control system is theoretically analyzed. Third, the simulation results are discussed. Finally, the conclusions are presented.

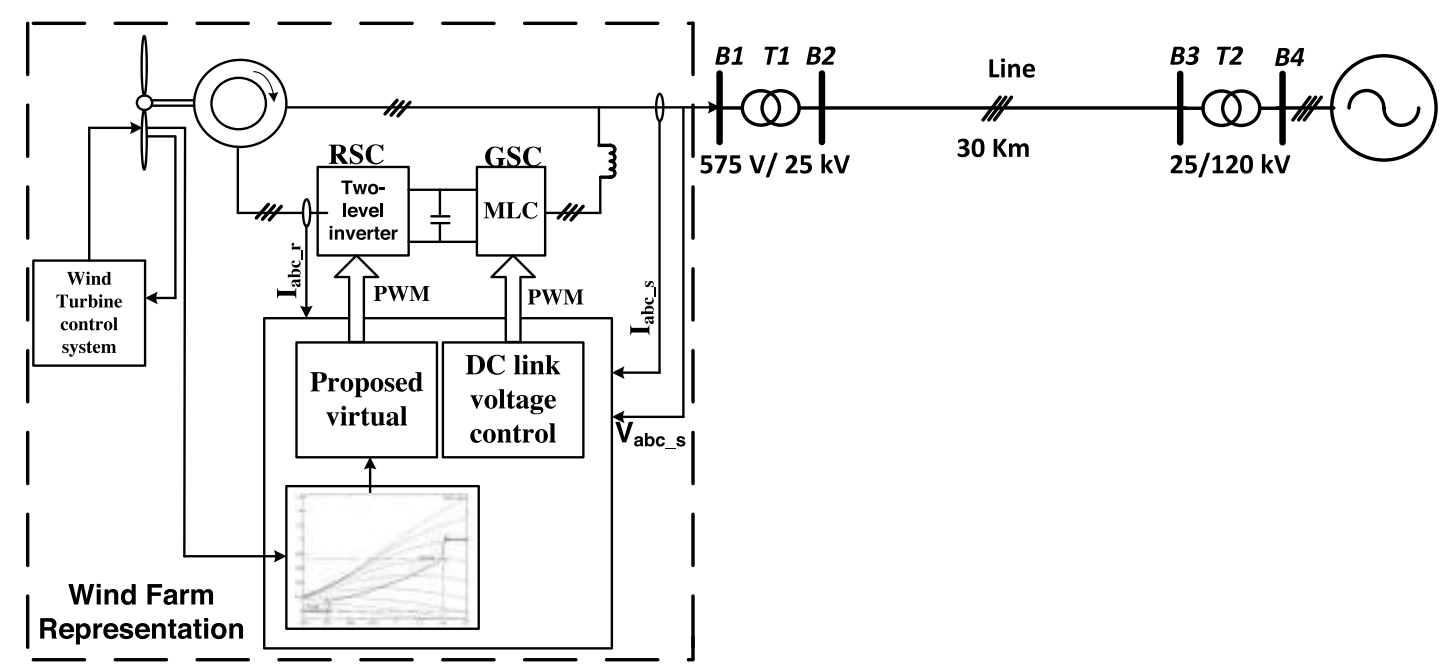

Figure 1. Schematic of the integration of the proposed virtual voltage control within the DFIG.

\section{Proposed Control Integration with LVRT}

The left-hand side of Figure 1 shows the complete schematic of the DFIG, and the right-hand side shows the grid representation. The DFIG includes the conventional converter at the rotor side connected back-to-back with the MLC at the grid side. It also includes an induction generator and wind turbine with its control system. In the wind turbine control system, the wind turbine pitch angle is adjusted on the basis of the wind speed value to extract the maximum power at the corresponding wind speed, as depicted by the red curve in Figure 1. The principle of this control is reported in detail in Tohidi et al. (2013). Three-phase grid currents, grid voltages, rotor currents, DC-link voltage, and wind speed are measured and sent to the control system. The following subsections explain the proposed virtual control to enhance the LVRT capability of the DFIG.

\section{PROPOSED CONTROL USING VIRTUAL VOLTAGE}

The proposed virtual voltage control block diagram placement is shown in Figure 1. For the DFIG, active and reactive powers are computed by Ahmed et al. (2019):

$$
P_{s}=-\frac{3}{2} \frac{L_{m}}{L_{m}+L_{s}} V_{s} i_{q r}
$$




$$
Q_{s}=\frac{3}{2} \frac{V_{s}}{L_{m}+L_{s}}\left(L_{m} i_{d r}-\frac{V_{s}}{\omega_{s}}\right)
$$

where $i_{q r}$ and $i_{d r}$ are the rotor currents on the direct and quadrature (d-q) axis, respectively; $L_{s}$ and $L_{m}$ are the stator leakage and mutual inductance, respectively; $\omega_{s}$ is the electrical angular speed; $V_{s}$ is the magnitude of the stator phase voltage. The d-q axis currents are presented in terms of active power, reactive power, and stator voltage, and the state space representation is

$$
\left[\begin{array}{c}
i_{d r} \\
i_{q r}
\end{array}\right]=K\left[\begin{array}{c}
\frac{Q_{s}}{V_{s}} \\
-\frac{P_{s}}{V_{s}}
\end{array}\right]+\left[\begin{array}{c}
V_{s} \\
L_{m} \omega_{s} \\
0
\end{array}\right],
$$

where $K=2\left(1+L_{s} / L_{m}\right) / 3$.

Equation (3) separately indicates the active and reactive power controls using the vector control with the directaxis oriented stator flux vector in the RSC. This process is achieved by regulating rotor currents $i_{q r}$ and $i_{d r}$ to control the active and reactive powers at their references, respectively. During a voltage dip due to faults in the network, the value $V_{s}$ in Equation (3) increases the rotor current components $i_{q r}$ and $i_{d r}$ that can damage the machine and increases the voltage on the DC-link between the two converters on the rotor side. The current should be limited up to the rated DFIG current to overcome this risk to the DFIG system. This condition is smoothly ascertained in the control system by replacing the $V_{s}$ with the virtual voltage rather than the actual voltages in Equation (3). This virtual voltage is designed and discussed as follows.

The effects of different voltage dips on the machine currents $\left(I_{d}\right.$ and $\left.I_{q}\right)$ are first evaluated using Equation (3) to design the virtual voltage profile. Figure 2 shows the effect of low generator voltage on the rotor currents at fixed controlled power (active and reactive) but at different power factors (0.8 and 1.0). In Figure 2, the d-q axis current components are remarkably affected by the reduction in the generator terminal voltages, and the total rotor currents are increased accordingly. Unfortunately, the lower voltage produces higher rotor currents. For machine voltage less than $0.4 \mathrm{pu}$, the total rotor current is increased to more than $1.8 \mathrm{pu}$. For severe reduction in the generator voltage at $0.2 \mathrm{pu}$, the rotor current is increased to around $3.5 \mathrm{pu}$. For significantly lower voltage, such as a three-phase fault close to the generator terminals, the rotor current is greater by seven times than the rated current. Under these lowvoltage conditions, the machine can be immediately damaged without the appropriate control. Although the machine's protection system can isolate the machine to prevent damage, the grid-code requirement is to keep the machine connected to the grid. Accordingly, the LVRT capability is attached to the machine during low grid-voltage conditions. In this study, this capability is achieved using the proposed virtual voltage-based control strategy at the RSC and by incorporating the MLC rather than the conventional converter at the grid side.

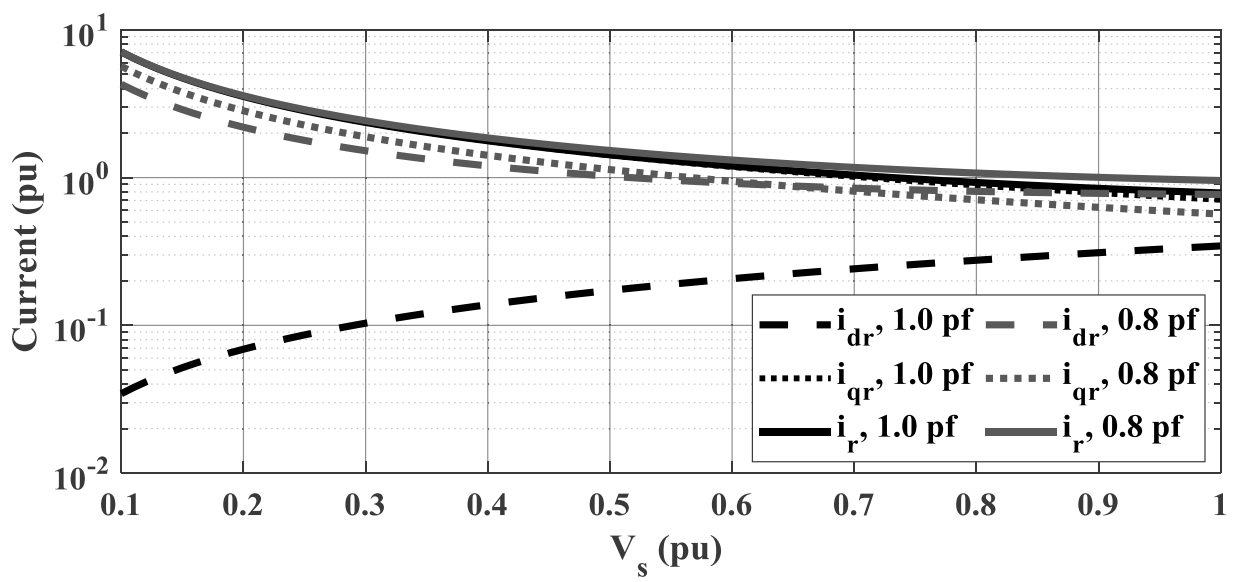

Figure 2. Inverse effects of the lower generator voltages on the rotor-side currents. 
The amplitude of the rotor current is governed by attaining the following current equation at unity per unit.

$I_{r}^{2}=I_{d r}^{2}+I_{q r}^{2}$

Substituting Equation (3) into Equation (4) yields

$I_{r}^{2}=K^{2} \frac{P_{s}^{2}+Q_{s}^{2}}{V_{s}^{2}}+\frac{2 K Q_{s}}{L_{m} \omega_{s}}+\frac{V_{s}^{2}}{\left(L_{m} \omega_{s}\right)^{2}}$

For optimum operation, $I_{r}$ should be $1 \mathrm{pu}$, and $P_{s}$ and $Q_{s}$ are considered references. Equation (5) can then be rewritten as

$V_{s}^{4}+\left(2 L_{m} \omega_{s} K Q_{s}-\left(L_{m} \omega_{s}\right)^{2}\right) V_{s}^{2}+K^{2}\left(L_{m} \omega_{s}\right)^{2}\left(P_{s}^{2}+Q_{s}^{2}\right)=0$.

Equation (6) is a second-order equation in terms of $V_{s}^{2}$, where the equation parameters are $a=1, b=$ $2 L_{m} \omega_{s} K Q_{s}-\left(L_{m} \omega_{s}\right)^{2}$, and $c=K^{2}\left(L_{m} \omega_{s}\right)^{2}\left(P_{s}^{2}+Q_{s}^{2}\right)$. Therefore, the root of Equation (6) is

$$
V_{s}= \pm \frac{1}{\sqrt{2}} \sqrt{-b \pm \sqrt{b^{2}-4 a c}}
$$

On the basis of solving Equation (6), the designed virtual voltage is presented in Figure 3 in accordance with different generated powers. The generator parameters assume that $L_{m}=2.9 \mathrm{pu}, L_{s}=0.18 \mathrm{pu}$, and $\omega_{s}=1 \mathrm{pu}$. Figure 3 shows the desired virtual voltage at 0.8 power factor and at different power operations, such as 1 and 0.5 pu with the current limited at $1 \mathrm{pu}$. For the unity power $(1 \mathrm{pu})$, the virtual voltage follows the actual voltage $\left(V_{s}\right)$ until $0.91 \mathrm{pu}$. However, the virtual voltage is fixed at $0.91 \mathrm{pu}$ for further voltage dips $\left(V_{s}<0.91\right)$. For the lower power $(0.5 \mathrm{pu})$, the virtual voltage can be fixed at $0.38 \mathrm{pu}$, even if the actual voltage is reduced. The value of $0.38 \mathrm{pu}$ is attained on the basis of the constraint for the machine current to not increase more than unity by solving Equation (6). The lower power operation contributes to lower operating current. When the voltage is reduced (voltage dip occurrence), the current is increased. However, the current reaches the rated value $(1 \mathrm{pu})$ when the voltage reaches $0.38 \mathrm{pu}$. Accordingly, the virtual voltage is fixed at $0.38 \mathrm{pu}$ for further lower voltage dips to keep the machine current at the rated current. From the curves, a dynamic performance of the designed virtual voltage is obtained in accordance with the power to limit the current at unity during network voltage dips.

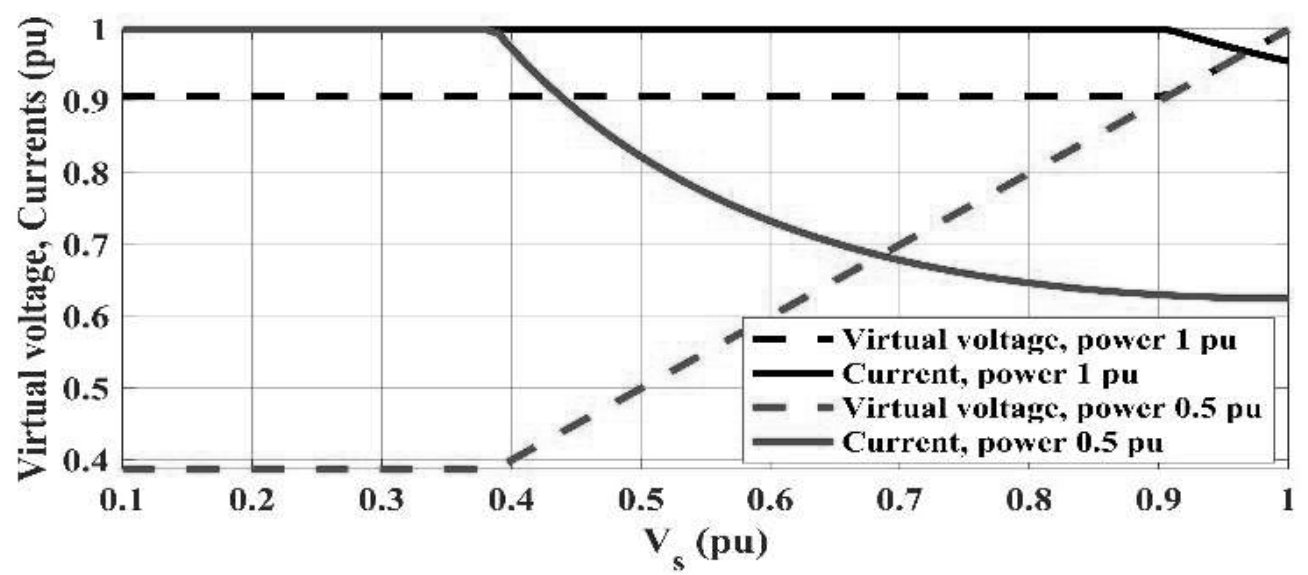

Figure 3. Designed virtual voltage performance for attaining the desired current of unity during voltage dips at 0.8 pu and different power operations. 
Figure 4 shows the implementation process of the proposed virtual voltage-based control to limit the generator currents during network voltage dips. It accordingly facilitates the LVRT capability of the DFIG during abnormal grid conditions (either remote or close faults). The reference powers and system voltages are continuously monitored and used for computing the rotor current using Equation (5). If the current is less than the unity, the control uses the actual voltage. Otherwise, the virtual voltage computed by Equation (6) is used. Considering this control principle, the generator currents are not increased more than the unity. The measured powers become the computed virtual powers because the virtual voltage is considered in the calculations of powers to be compared with reference powers. These computed virtual powers are based on limiting the generator currents up to the unity values. The LVRT capability of the DFIG is attained during network voltage dips. Incorporating the proposed control for the LVRT operation of the DFIG is discussed in the following subsection.

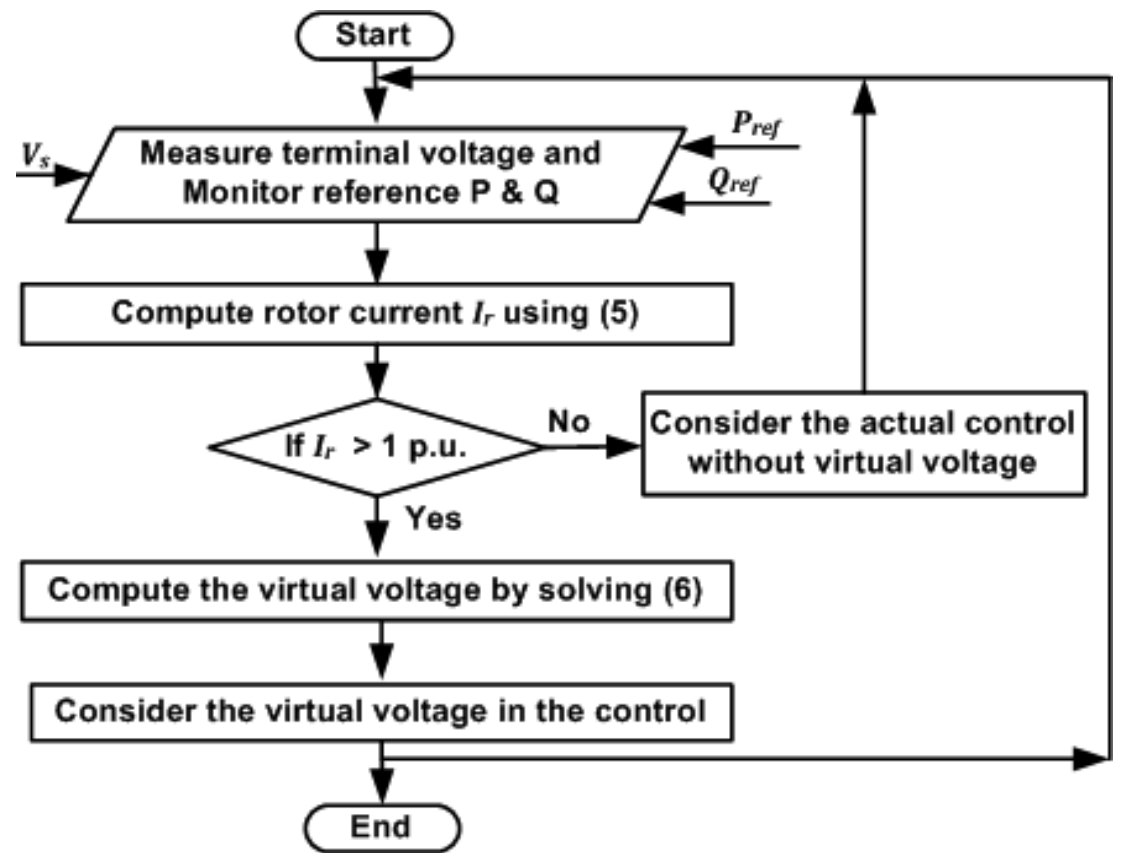

Figure 4. Implementation of the proposed virtual voltage control.

\section{INTEGRATING THE VIRTUAL VOLTAGE CONTROL.}

Figure 5 shows the block diagrams of the GSC and RSC controls. Figure 5(a) shows that the GSC currents $\left(I_{a}, I_{b}, I_{c}\right)$ are converted to their d-q components, $I_{q g c}$ and $I_{d g c}$, to simulate the DC-control values. The DC bus voltage between the two converters is used to control the injected power into the grid by calculating the grid-side direct-axis current component. The injected reactive power into the grid is assumed to be zero. This process is performed by equating $I_{q g c}$ to zero. The d-q reference components of the grid-side voltage $\left(V_{q g c_{-} \text {ref }}\right.$ and $V_{\text {dgc } \_ \text {ref }}$ ) can be calculated, in which they are fed to the space vector control algorithm to generate the switching pulses to control the MLC. 


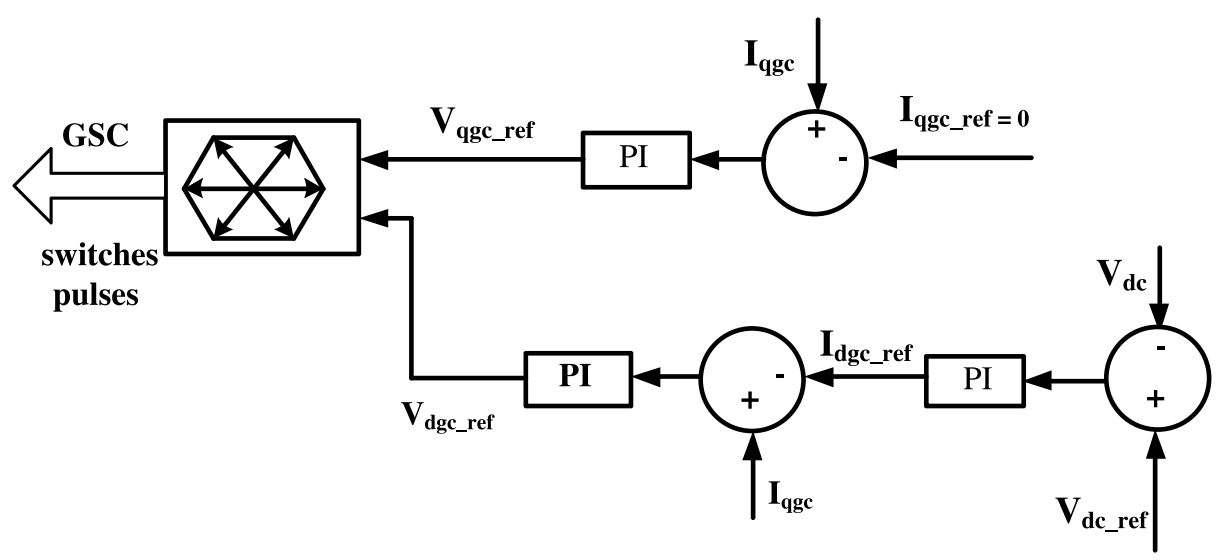

(a) GSC control.

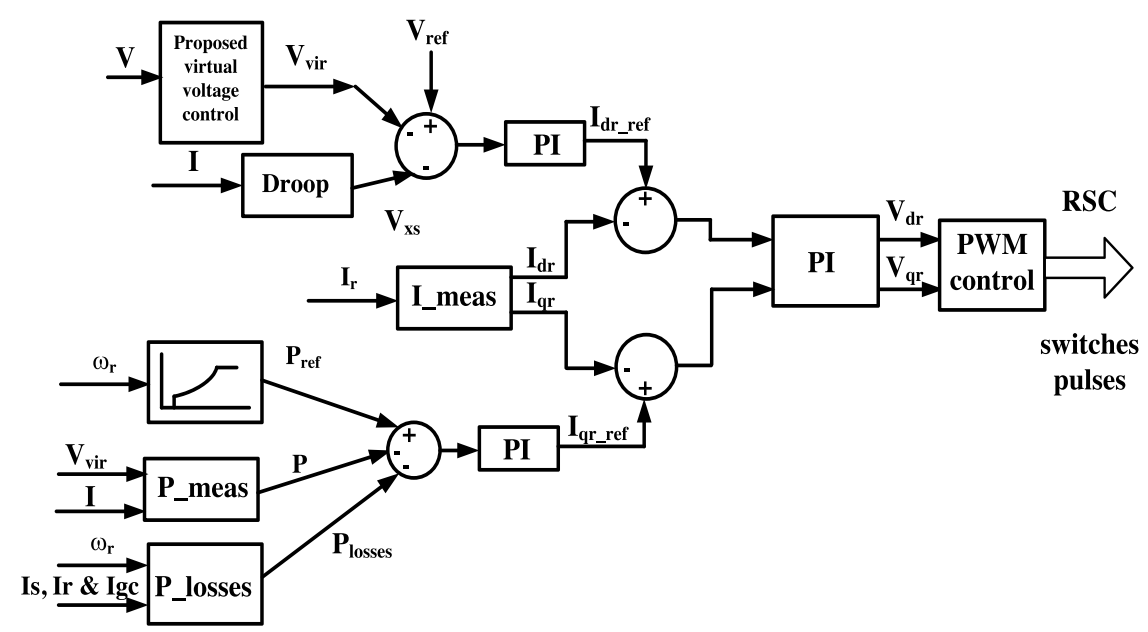

(b) RSC control.

Figure 5. Proposed control interaction with LVRT block diagram.

In Figure 5(b), which shows the RSC control block diagram, the rotor voltage is fed to the virtual power control algorithm described in the previous subsection to generate the virtual voltage. The virtual voltage and the voltage drop across the rotor reactance are subtracted from the rotor reference voltage to generate the reference rotor direct-axis current component $I_{d r_{-} \text {ref }}$ On the other side, the rotor virtual power is calculated using the rotor current and the virtual voltage. The rotor power losses are also calculated. The rotor speed is used to generate the rotor reference power. The reference rotor quadrature-axis current component $I_{q r_{-} \text {ref }}$ is calculated by subtracting the rotor virtual power and rotor power losses from the rotor reference power. The measured rotor currents are transformed to the d-q axis current components $I_{d r}$ and $I_{q r}$. The errors between rotor current components are fed to the classical proportional-integral (PI) controls to generate the rotor voltage components $V_{d r}$ and $V_{q r}$. These voltage components are fed to the pulse width control module to generate rotor converter switch pulses.

\section{MLC INCORPORATED IN DFIG}

The MLC is introduced to improve the performance of the DFIG during abnormal conditions at the grid with the aid of the proposed virtual control. The MLC is proposed at the grid side to improve the performance of the injected power into the grid and to achieve high power ratings. However, the proposed MLC uses extra switches that may increase the system prices. The overall system should be considered to obtain an overview about the percentage 
increase in the total cost of the energy conversion system due to the utilization of MLC rather than the conventional one. The schematic of the DFIG integration is shown in Figure (1). The system construction contains the wind turbine, induction machine, two converters at the third ratings of the machine, and power transformer. A single converter price is significantly lower with respect to the overall energy conversion system. The MLC has 12 extra switches compared with the conventional one. These extra switches reduce the ratings of all switches in the MLC. The prices of extra switches are insignificant.

The space vector pulse width modulation (SVPWM) (Hasan et al., 2014; Sebtahmadi et al., 2015; Kumar et al., 2017) becomes a more attractive control technique among the other control methods applied to MLCs. This condition is due to two main features: the SVPWM is simple, and the hardware is easily implemented with a digital controller. In the SVPWM, the three-phase AC voltages are transformed into rotating space vectors in the complex plane. At each instant, the available voltages from the MLC can be generated using the nearest three vectors and their switching times.

Figure 6(a) shows the MLC topology adopted for this application. This topology is called a hybrid MLC (Edpuganti et al., 2015; Zhang et al., 2017) and consists of a main circuit and three auxiliary circuits. The main circuit is the conventional three-phase six-switch converter. The other auxiliary circuits are the conventional single-phase full bridge converters. Each single auxiliary circuit is connected in series with one arm of the main circuit. Four DC sources are found: one main DC source for the main circuit and three equal and isolated DC sources for the auxiliary circuits. The ratio between the main DC source and the auxiliary DC source is chosen to be 3:1.

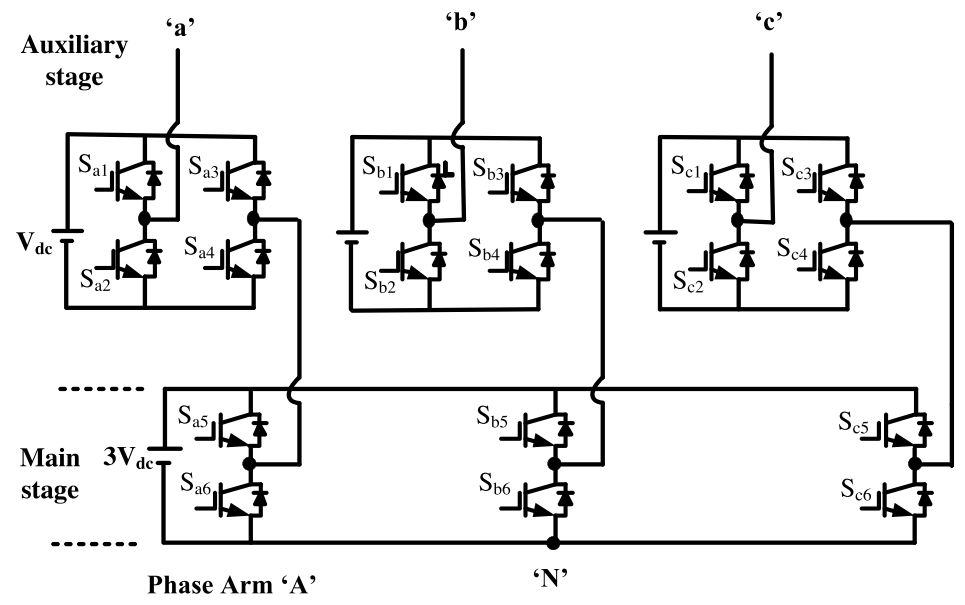

(a) Main power circuit

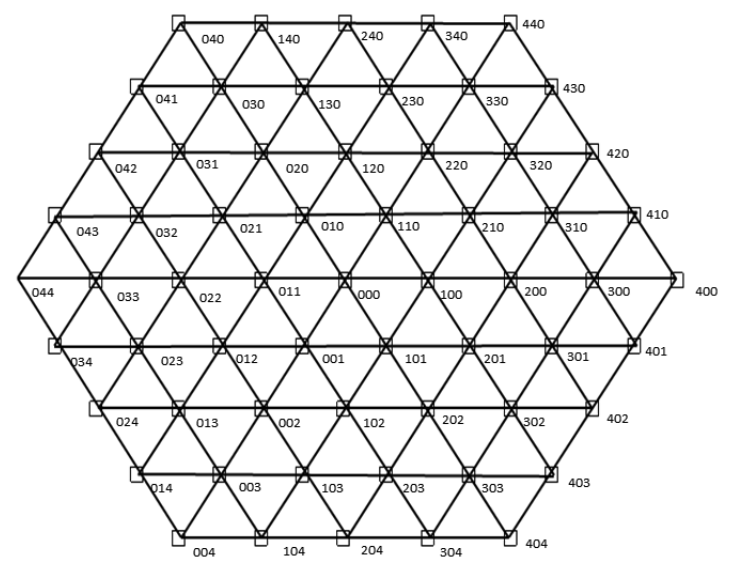

(b) Sixty-one available and normalized states in a d-q complex reference plane

Figure 6. Topology and state representation of a hybrid MLC. 
The main converter circuit can generate three levels $\left(-3 V_{\mathrm{dc}}, 0,3 V_{\mathrm{dc}}\right)$, and each of the auxiliary circuits can generate three levels $\left(-V_{\mathrm{dc}}, 0, V_{\mathrm{dc}}\right)$. Therefore, connecting the main circuit in cascade with the auxiliary circuits generates nine levels of line-to-line output voltage waveform $\left(-4 V_{\mathrm{dc}},-3 V_{\mathrm{dc}},-2 V_{\mathrm{dc}},-V_{\mathrm{dc}}, 0, V_{\mathrm{dc}}, 2 V_{\mathrm{dc}}, 3 V_{\mathrm{dc}}, 4 V_{\mathrm{dc}}\right)$, representing the highest output voltage resolution for this topology. The switching states for the pole voltages, $\mathrm{v}_{\mathrm{an}}$, are given in Table 1.

Table 1. Available states of pole voltage $v_{a n}$

\begin{tabular}{|c|c|c|c|c|c|c|}
\hline \multirow[b]{2}{*}{$v_{a n}$} & \multicolumn{6}{|c|}{ Switches of arm "A" } \\
\hline & Sa1 & $\mathrm{Sa2}$ & $S a 3$ & Sa4 & $S a 5$ & Sa6 \\
\hline $0 V_{\mathrm{dc}}$ & 1 & 0 & 1 & 0 & 0 & 1 \\
\hline $1 V_{\mathrm{dc}}$ & 1 & 0 & 0 & 1 & 0 & 1 \\
\hline $2 V_{\mathrm{dc}}$ & 0 & 1 & 1 & 0 & 1 & 0 \\
\hline $3 V_{\mathrm{dc}}$ & 1 & 0 & 1 & 0 & 1 & 0 \\
\hline $4 V_{\mathrm{dc}}$ & 1 & 0 & 0 & 1 & 1 & 0 \\
\hline
\end{tabular}

The well-known space vector modulation (SVM) (Sebtahmadi et al., 2015; Noman et al., 2017; Kumar et al., 2017) control algorithm is used for the MLC to generate the switching pulses. Table 1 indicates that each pole voltage has 5 different switching states $\left(0, V_{\mathrm{dc}}, 2 V_{\mathrm{dc}}, 3 V_{\mathrm{dc}}, 4 V_{\mathrm{dc}}\right)$; therefore, up to 125 possible voltage states can be synthesized. These 125 states have 61 unique switching states, in addition to 64 redundancy states. Figure 8 shows the 61 available voltage vectors and their bands that can be generated. Four bands based on the amplitude of the space vector are found. These bands have $6,12,18$, and 24 vectors, in addition to the zero vectors, all forming 61 unique vectors. Many SVM techniques have been proposed to generate switching pulses on the basis of the command d-q reference frame voltages. These techniques have common steps that can be summarized as follows.

Step 1: The three-phase reference voltages are calculated from the system and converted into a d-q complex reference frame called a reference space vector as follows:

$$
V_{S V}=v_{a N}+e^{\frac{j 2 \pi}{3}} v_{b N}+e^{\frac{j 4 \pi}{3}} v_{c N}
$$

Step 2: The space vector in Equation (8) is then normalized by dividing it to the DC step voltage (equal to $V_{\text {dc }}$ ) as follows:

$$
V_{S V N}=\left(\frac{1}{V_{d c}}\right) *\left(V_{S V}\right)=V_{S V d}+j V_{S V q} .
$$

Step 3: The normalized reference vector, $V_{S V N}$, is then plotted inside the available d-q frame, and its head is located, as shown in Figure 6(b). This step is conducted by calculating the amplitude and angle of $\mathrm{V}_{\mathrm{SVN}}$ as follows:

$$
\left|V_{S V N}\right|=\sqrt{V_{S V d}^{2}+V_{S V q}^{2}} \text { and } \theta=\tan ^{-1}\left(\frac{V_{S V q}}{V_{S V d}}\right) \text { (four quadrant angle). }
$$

Step 4: The nearest three vectors to the head of $\mathrm{V}_{\mathrm{SVN}}$ can be defined as $V_{1}, V_{2}$, and $V_{3}$.

Step 5: The switching states are then defined immediately, and their switching times $\left(T_{1}, T_{2}\right.$, and $\left.T_{3}\right)$ can be calculated by

$$
T_{1} * V_{1}+T_{2} * V_{2}+T_{3} * V_{3}=T * V_{\mathrm{SVN}}
$$




$$
T_{1}+T_{2}+T_{3}=T
$$

where $=1 / f_{\mathrm{s}}$, and $f_{\mathrm{s}}=$ switching frequency.

\section{SIMULATED SYSTEM}

Figure 1 illustrates the wind farm of six 1.5 MW DFIG-based wind turbines connected to the power grid at a voltage level of $575 \mathrm{~V}$ through a power transformer of $0.575 / 25 \mathrm{kV}$, a $30-\mathrm{km}$ power line, and a power transformer of 25/120 kV (Rashid et al., 2015; Alsmadi et al., 2018). The 120-kV grid is represented by a voltage source behind an impedance where the voltage dip is achieved by reducing the source voltages. In the DFIG, two converters are used: the GSC and the RSC. The GSC is represented by the MLC during the inversion mode, whereas it is represented by a conventional two-level three-phase converter during the conversion mode of operation. The RSC is represented by a conventional two-level converter. The RSC is controlled by the proposed virtual voltage control, whereas the GSC is controlled by a DC-link voltage control. The system performance is discussed in the next section.

\section{PERFORMANCE DURING 0.01 PU VOLTAGE DIP AT BUSBAR B4}

Considering an extreme voltage reduction of $0.01 \mathrm{pu}$ at busbar B4 (network in Figure 1), Figures 7, 8, and 9 show the corresponding performance of a DFIG with the incorporation of a MLC and the proposed LVRT based on virtual voltage control. In Figure 7, the generator terminal voltages are reduced during an extreme low grid voltage $(0.01 \mathrm{pu}$ at busbar B4), as depicted in Figure 7(a). The stator and rotor currents (AC components) are limited at unity, as shown in Figures 7(b) and 7(c), respectively. However, current transients are found at the voltage dip and rise instances (at 1 and $1.2 \mathrm{~s}$ in Figure 7). Based on the control effect, the DC voltage shown in Figure 7 is unchanged or fixed at its designed value, although small fluctuations are accepted at the dip and rise instances.

Figure 8 shows the comparison between the actual and virtual powers during the normal operation and voltage reduction periods. During the normal period of operation, the actual and virtual powers are identical, as depicted in Figures 8(a) and 8(b), respectively. However, during the grid-voltage dip period, the virtual powers are different from the actual powers, where the actual powers are reduced to attain the unity generator currents and desired DC voltage, as shown in Figure 8. Figure 8(c) shows the corresponding rotor speed that is affected by the voltage dip period. Figure 9 shows the performance of the MLC where the converter is operated in nine levels during the normal operation period, whereas it is reduced to four and two levels during the voltage dip period. This figure confirms the MLC interaction with the proposed control during low grid-voltage conditions.

\section{PERFORMANCE DURING 0.5 PU VOLTAGE DIP AT BUSBAR B4}

Figure 10 shows the performance during 0.5 pu voltage dip at busbar B4. As this disturbance is lower than the previous one (comparison of Figures 7(a) and 10(a)), the performance is better when attaining the conditions of limiting the generator currents at unity and limiting the DC voltage (comparison of Figures 7(b), 7(c), and 7(d) with Figures 10(b), 10(c), and 10(d), respectively). The active and reactive power and the rotor speed of the generator are slightly affected (comparison of Figures 8 and 11). The MLC operated at four levels during the low-voltage operation of $0.5 \mathrm{pu}$ is observed (comparison of Figures 9 and 12). The performance shown in Figures 7 to 12 ensures the successful operation of the proposed LVRT. Accordingly, the electric generation system, including the DFIG, GSC, RSC, and DC-link, is safely operated with the grid during normal operation and abnormal conditions that are represented by voltage dips. 


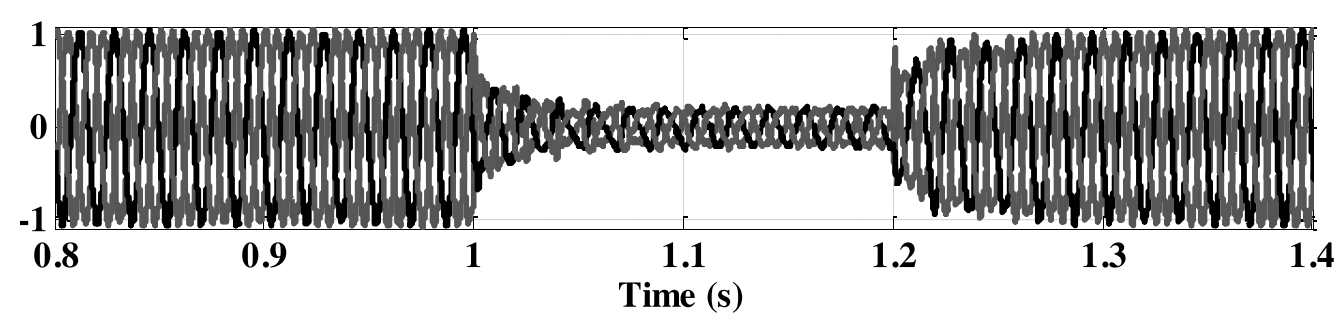

(a) DFIG terminal voltage (pu)

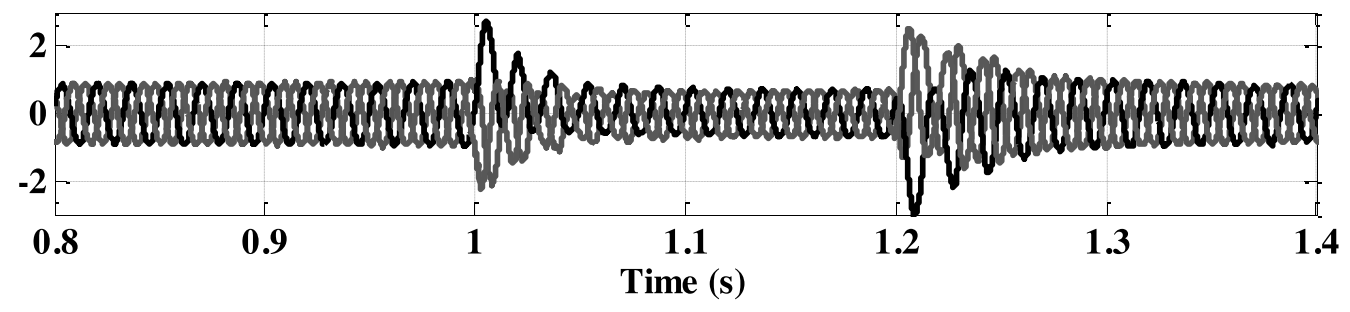

(b) DFIG terminal current (pu)

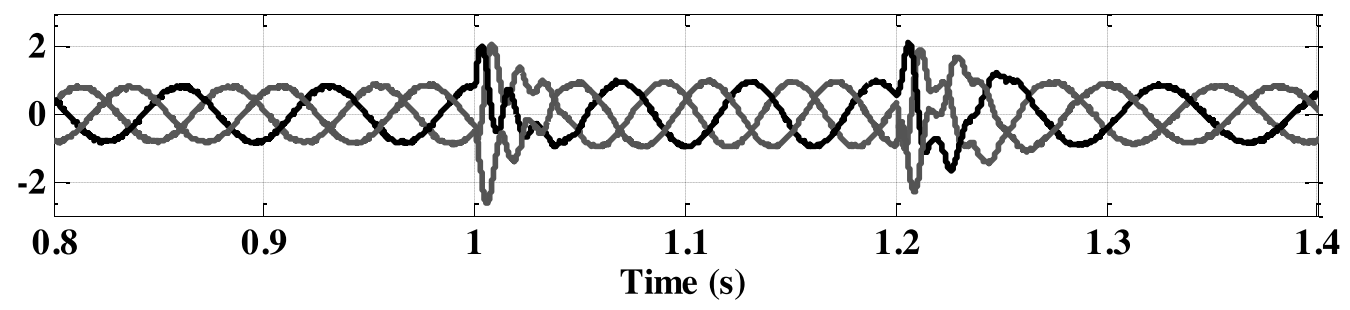

(c) Rotor current (pu)

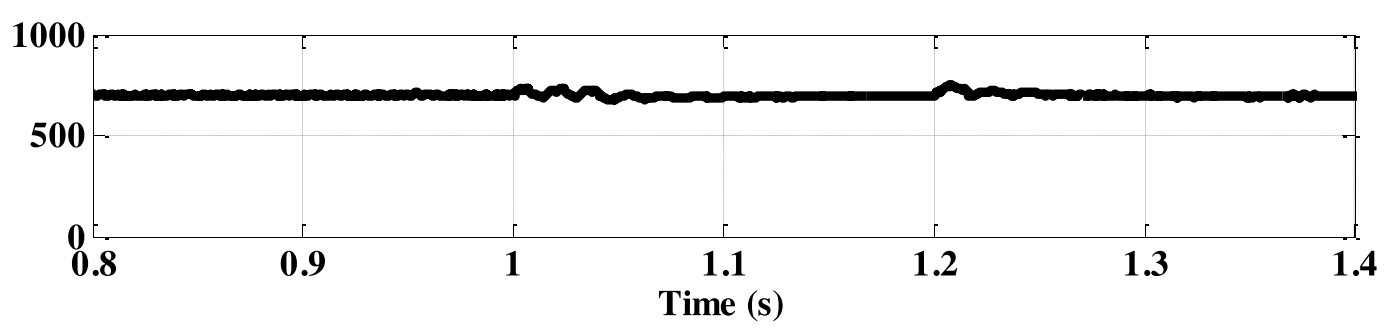

(d) DC main bus voltage (700 V rating voltage)

Figure 7. Performance due to 0.01 pu voltage dip at busbar B4. 


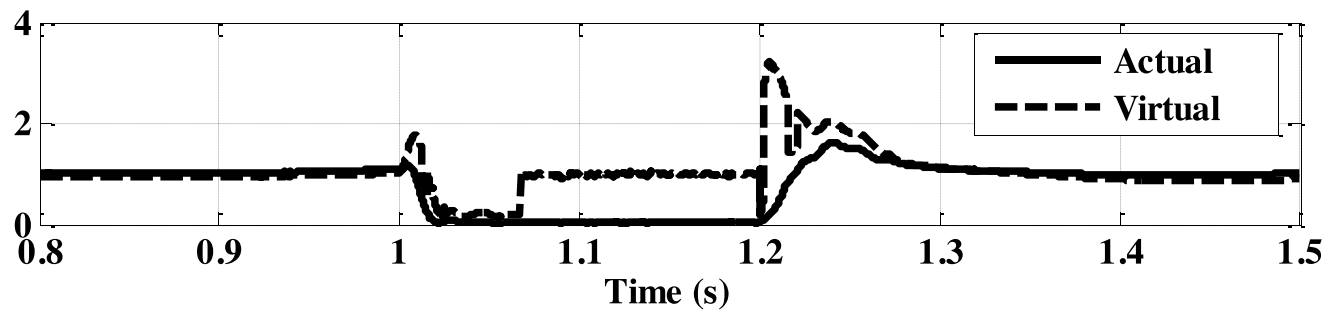

(a) Active power (pu)

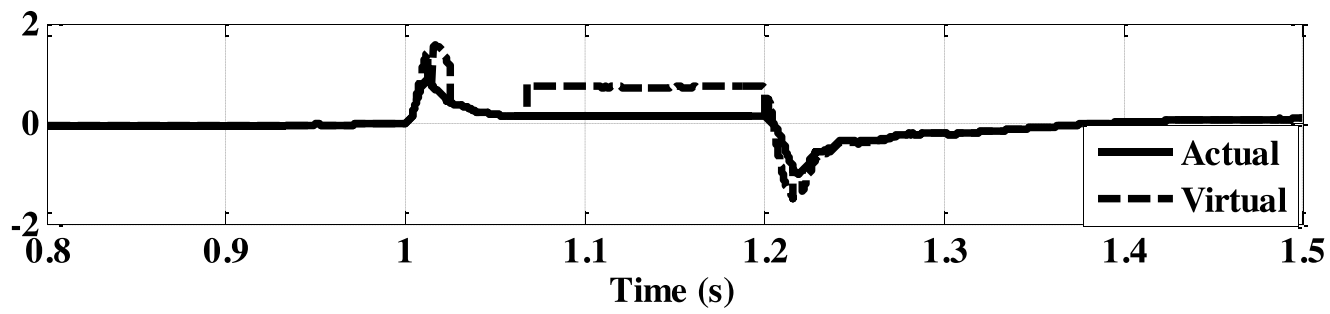

(b) Reactive power (pu)

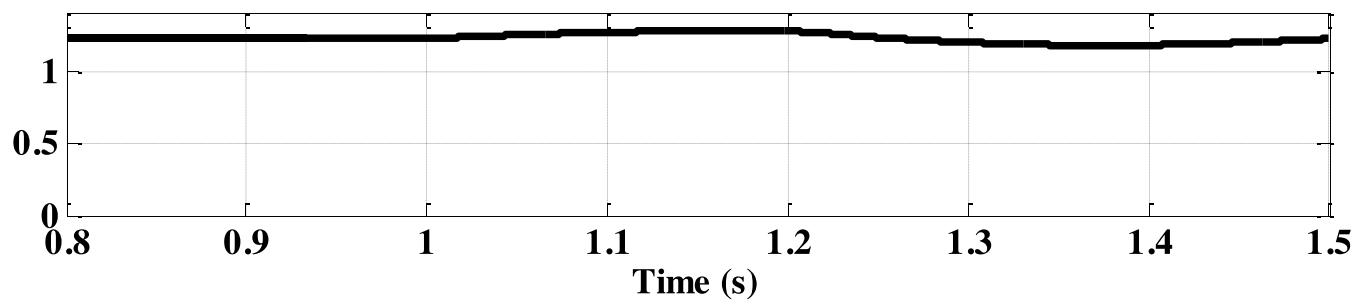

(c) Rotor speed (pu)

Figure 8. Power and rotor speed due to 0.01 pu voltage dip.

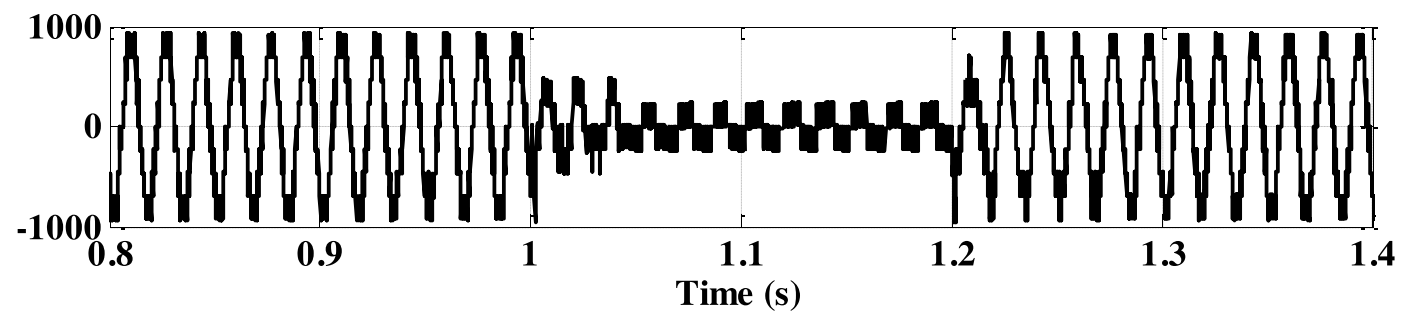

Figure 9. MLC output voltage performance due to 0.01 pu voltage dip at busbar B4. 


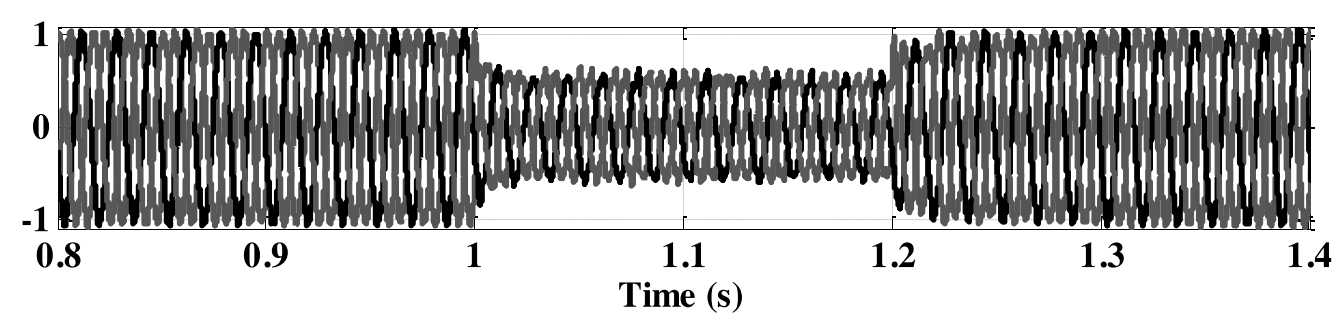

(a) DFIG terminal voltage (pu)

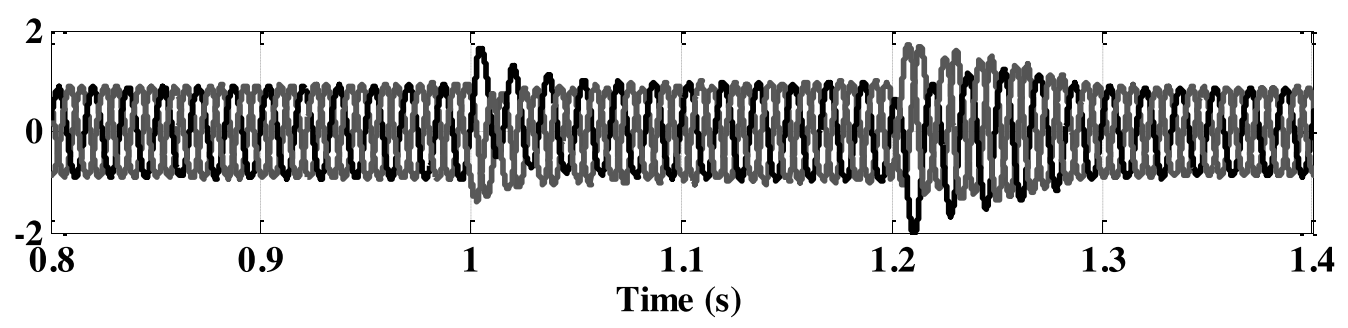

(b) DFIG terminal voltage current $(\mathrm{pu})$

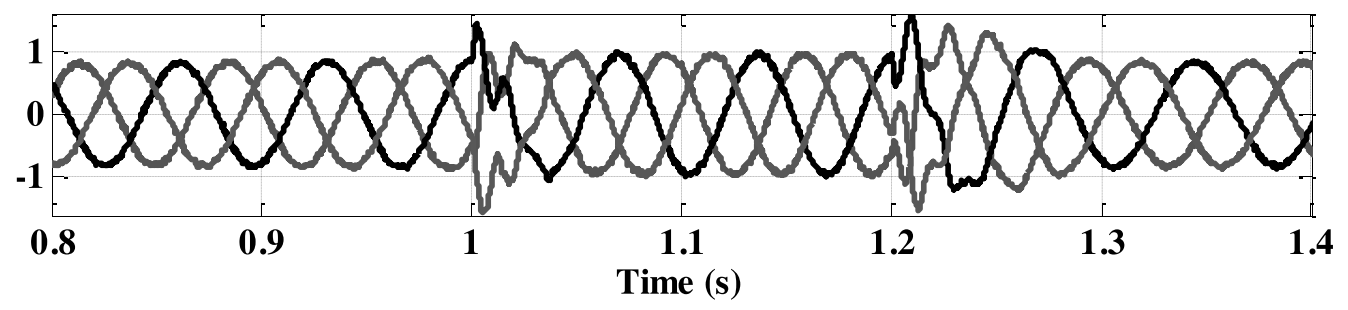

(c) Rotor current (pu)

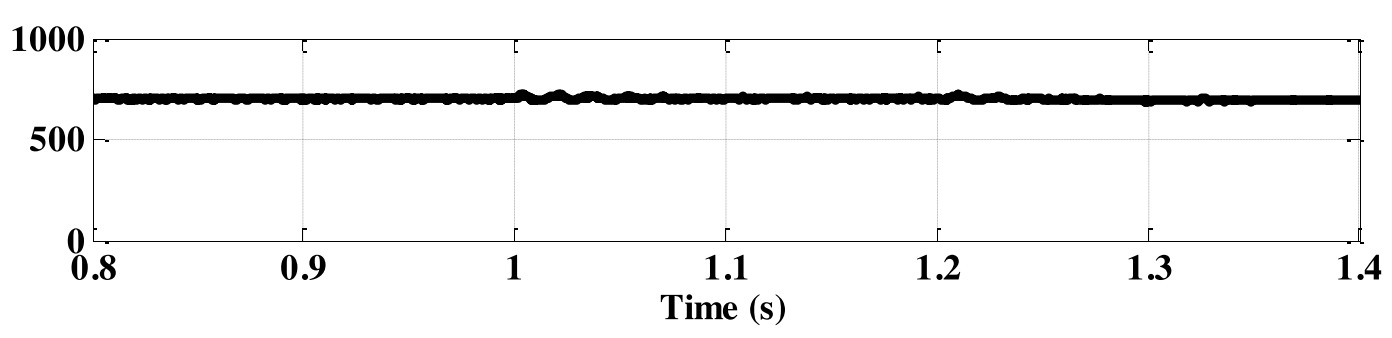

(d) DC main bus voltage (700V rating voltage)

Figure 10. Performance due to voltage dip 0.5 pu at busbar B4. 


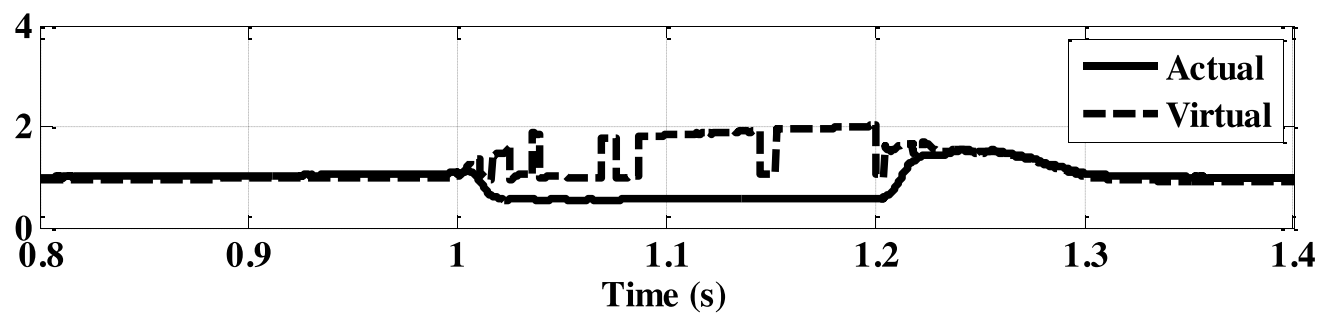

(a) Active power (pu)

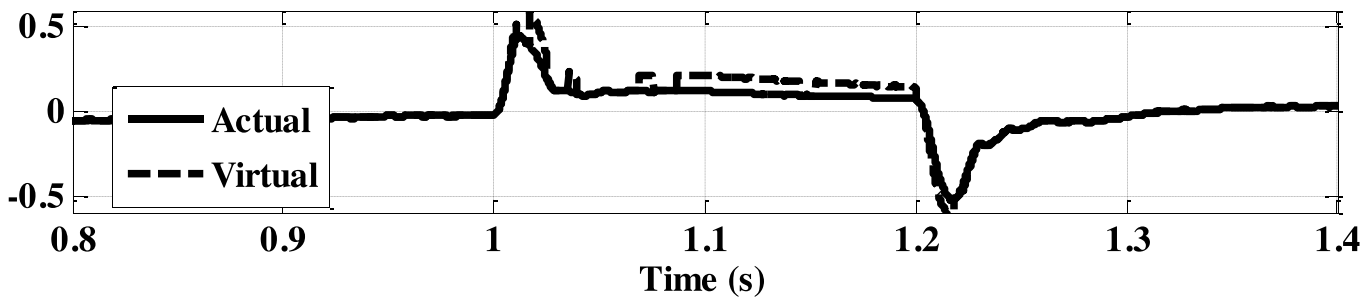

(b) Reactive power (pu)

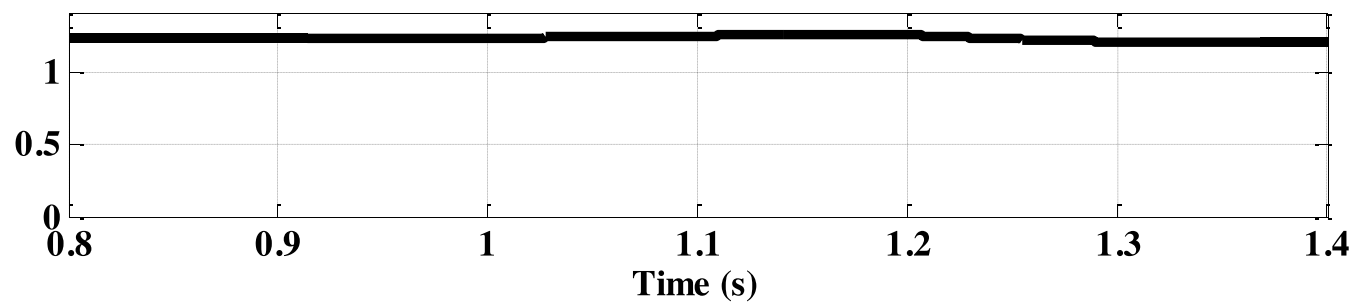

(c) Rotor speed (pu)

Figure 11. Power and rotor speed due to 0.5 pu voltage dip.

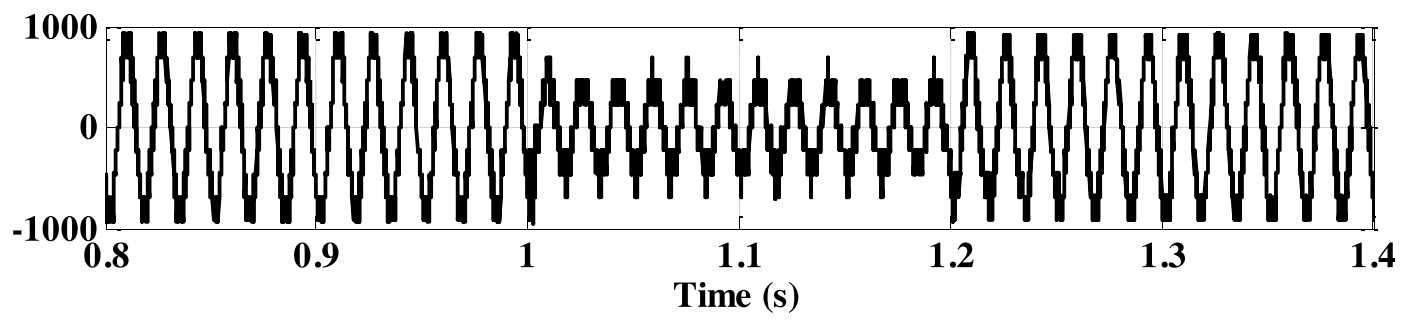

Figure 12. MLC performance due to 0.5 pu voltage dip at busbar B4. 


\section{PERFORMANCE DURING CLOSE THREE-PHASE FAULT AT BUSBAR "B2"}

Figures 13 to 16 show the performance during extreme three-phase fault at busbar "B2". This is to evaluate the performance during very close voltage dip source. The fault resistance is considered $0.1 \Omega$ and corresponding busbar "B2" voltage waveforms and busbar "B2" current from the grid side are presented in figure 13. During the fault period ( 0.3 to $0.6 \mathrm{~s}$ ), the busbar voltages are diminished, and the grid currents measured at Busbar "B2" are increased. During this disturbance, the DFIG generator voltage is reduced as shown in Figure 14(a). However, the generator and rotor currents are not increased and kept constant close to the rated value except the transient of DC decay component at the beginning of fault occurrence as depicted in Figures 14(b) and 14(c), respectively. Consequently, the DC voltage shown in Figure 14(d) is not approximately affected during this extreme fault case. The rotor speed of the generator is slightly affected as depicted in Figure 15, and the MLC operated at two levels during the three-phase fault disturbance as shown in Figure 16. Such performances ensure the proposed controlled MLC capability to safely operate the wind energy conversion system during severe disturbances of extreme low voltages troubles.

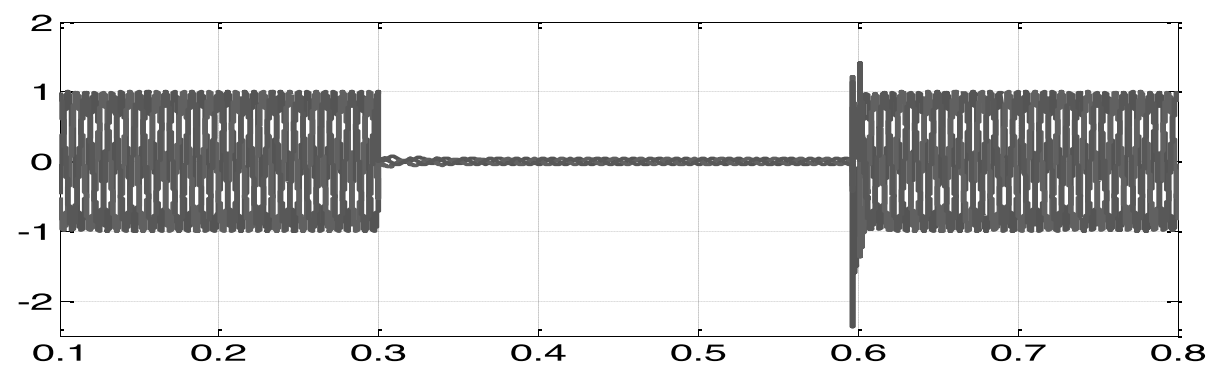

(a) Busbar B2 voltage (pu)

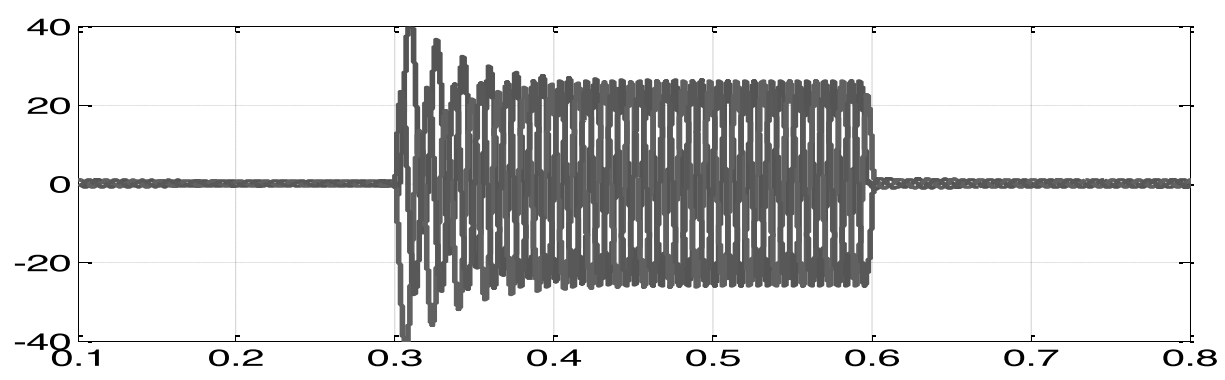

(a) Busbar B2 currents from the grid side (pu)

Figure 13. The waveforms at three-phase faulted Busbar B2. 


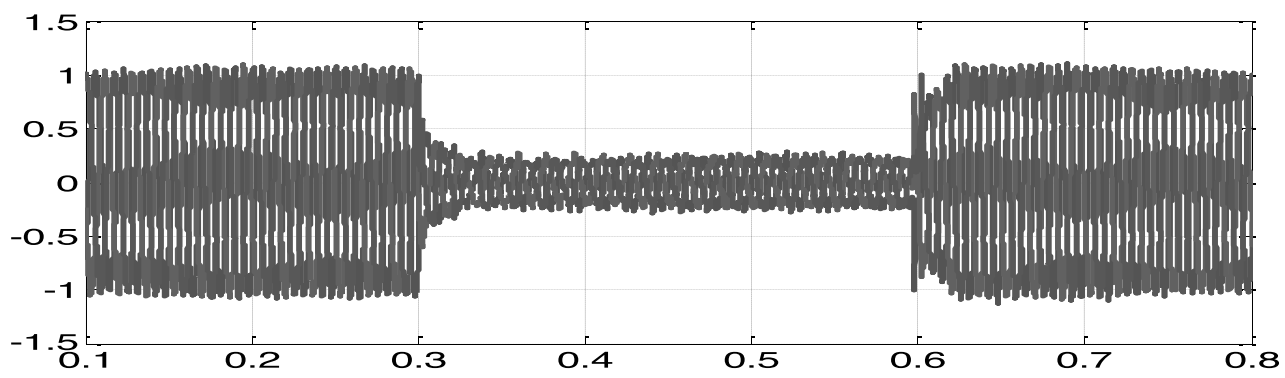

(a) DFIG terminal voltage (pu)

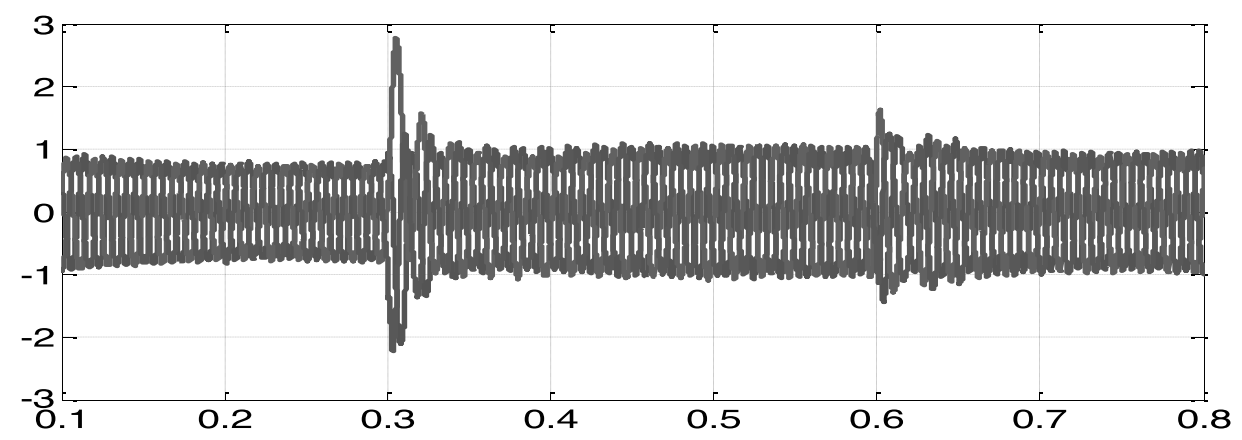

(b) DFIG terminal currents $(\mathrm{pu})$

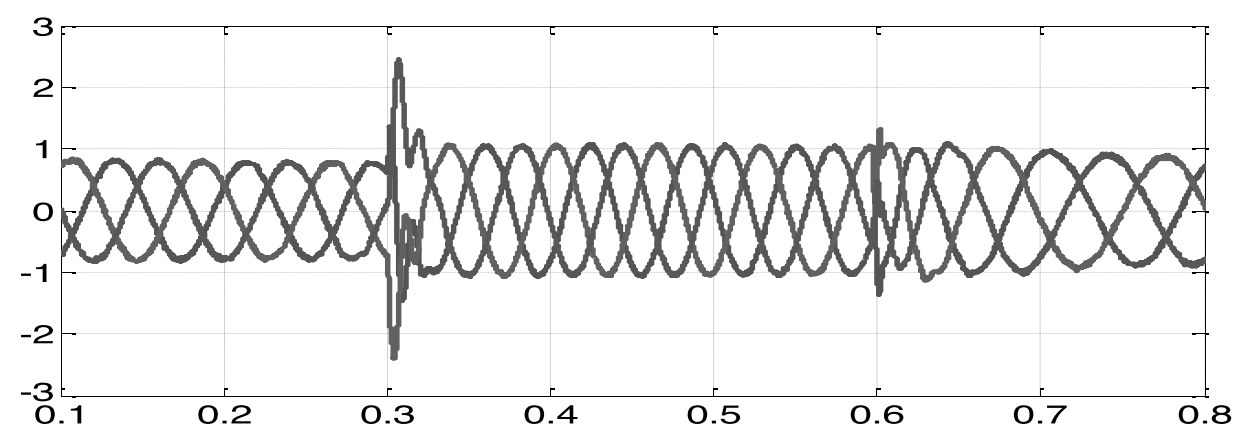

(c) Rotor currents (pu)

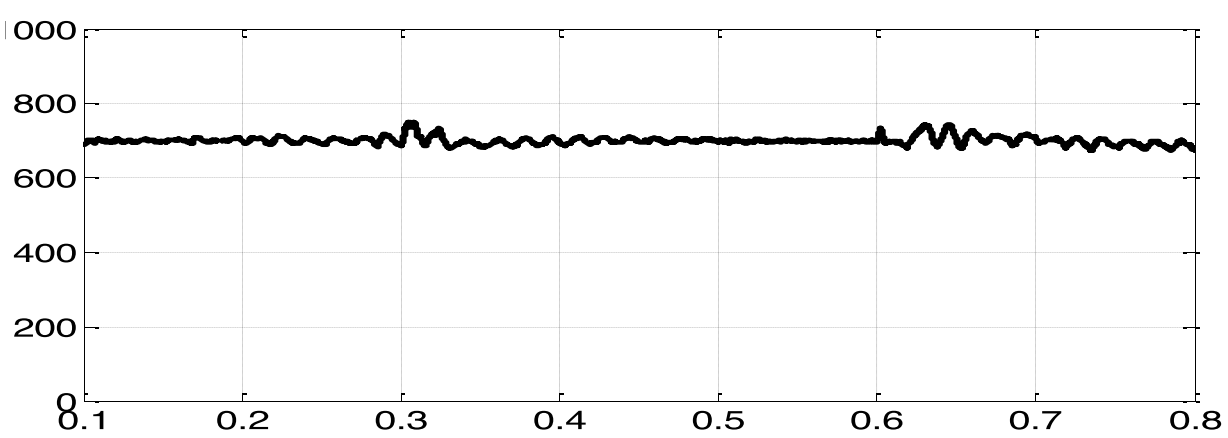

(d) DC main bus voltage (700 V rating voltage)

Figure 14. Performance due to three-phase fault at Busbar B2. 


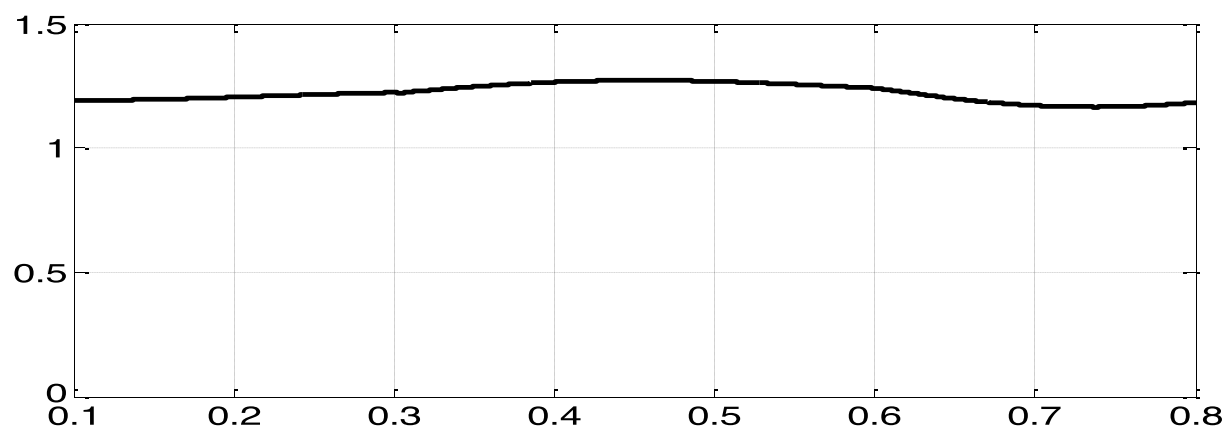

Figure 15. Rotor speed due to the three-phase fault at Busbar B2.

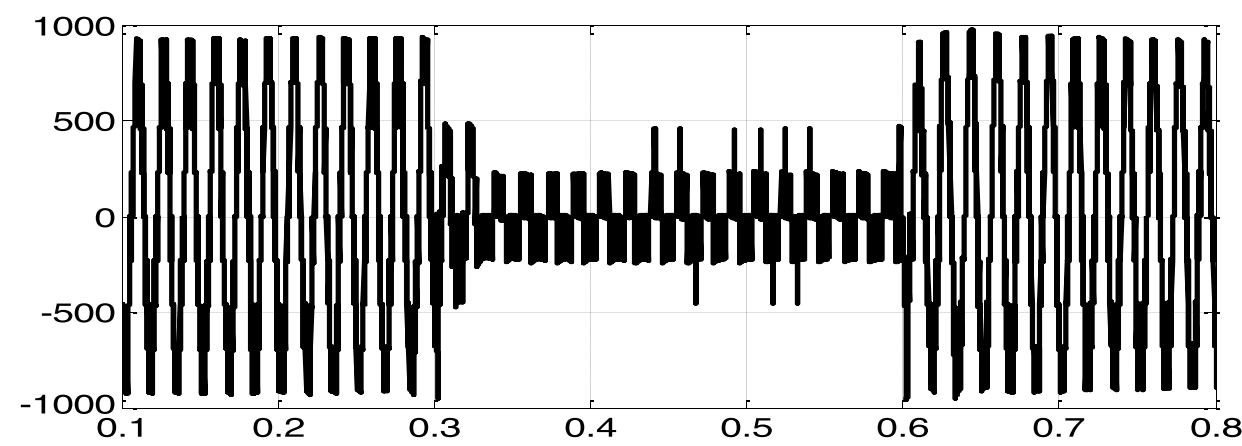

Figure 16. MLC output voltage due to the three-phase fault at Busbar B2.

\section{CONCLUSION}

A virtual voltage concept for the DFIG was designed to control the two-level converter connected at the rotor side. A nine-level hybrid MLC was adopted and interconnected at the grid side. The MLC topology included the main circuit and auxiliary three circuits where the switching pulses are generated using the well-known SVM. Although this topology increases the considered number of electronic power devices, the voltage is distributed with a ratio of 3:1. This condition reduces the planned rating voltages of the devices and the added cost due to MLC usage. The analytical derivation of the proposed virtual voltage is given in the form of limiting the rotor currents at the rated values. This proposal is implemented to enhance the LVRT capability of DFIG-based wind turbines. The proposed virtual control and MLC using six 1.5 MW DFIG-based wind turbines connected to the power grid are implemented. The comparison between the actual and virtual powers proves that the operation of virtual voltage control in combination with a MLC is a good solution for enhancing the LVRT system capability. The virtual voltage control provides lower transient active and reactive powers than the virtual, thereby enhancing the rated generator currents and rated DC voltages during LVRT operation. The simulation waveforms captured confirm an enhanced performance during extreme low grid voltages.

\section{ACKNOWLEDGMENT}

The authors would like to acknowledge the financial support received from Taif University Researchers Supporting Project Number (TURSP-2020/146), Taif University, Taif, Saudi Arabia. 


\section{REFERENCES}

Abad, G., López, J., Rodríguez M., Marroyo, L. \& Iwanski, G. 2011. Doubly Fed induction machine: modeling and control for wind energy generation. Wiley-IEEE Press, Hoboken, NJ, USA.

Ahmed, M., Metwaly, M. \& Elkalashy, N. 2019. Performance Investigation of Multi-Level Inverter for DFIG during Grid Autoreclosure Operation. International Journal of Power Electronics and Drive Systems (IJPEDS), 10(1): 454-462.

Alsmadi, Y., Xu, L., Blaabjerg, F., Piña Ortega, A.J., Abdelaziz, A.Y., Wang, A. \& Albataineh, Z. 2018. Detailed Investigation and Performance Improvement of the Dynamic Behavior of Grid-Connected DFIG Based Wind Turbines under LVRT Conditions. IEEE Transactions on Industrial Applications, 54(5): 4795-4812.

Amalorpavaraj, R., Kaliannan, P., Padmanaban, Subramaniam, U. \& Ramachandaramurthy, V. K. 2017. Improved Fault Ride Through Capability in DFIG Based Wind Turbines Using Dynamic Voltage Restorer with Combined Feed-Forward and Feed-Back Control. IEEE Access, 5: 20494-20503.

Colak, I., Kabalci, E., Bayindir, R. 2011. Review of multilevel voltage source inverter topologies and control schemes. Energy Conversion and Management, 52:1114-1128.

Debnath, S., Qin, J., Bahrani, B., Saeedifard, M. \& Barbosa, P. 2015. Operation, Control, and Applications of the Modular Multilevel Converter: A Review. IEEE Transactions Power Electronics, 30(1): 37-53.

Edpuganti, A., Rathore, A. 2015. A Survey of Low Switching Frequency Modulation Techniques for MediumVoltage Multilevel Converters. IEEE Transactions on Industrial Applications, 51(5): 4212-4228.

El-Naggar, A. Erlich, I. 2017. Short-circuit current reduction techniques ofthe doubly-fed induction generator based wind turbines for fault ride through enhancement IET Renewable Power Generation, 11(7): 1033-1040.

FERC - Interconnection of Wind Energy, 18 CFR Part 35, Docket No. RM05-4-001; Order No. 661-A December 12, 2005.

Gadalla, A., Yan, X., Altahir, S. \& Hasabelrasul H. 2017. Evaluating the capacity of power and energy balance for cascaded H-bridge multilevel inverter using different PWM techniques. The Journal of Engineering, 13: 1713-1718.

Hasan, M., Mekhilef, S., \& Ahmed, M. 2014. Three-phase hybrid multilevel inverter with less power electronic components using space vector modulation. IET Power Electronics, 7: 1256-1265.

Hu, J. \& He, Y. 2009. Reinforced control and operation of DFIG-based wind power generation system under unbalanced grid voltage conditions. IEEE Transactions on Energy Conversion, 24(4): 905-915.

Kumar, A. \& Chatterjee, D. 2017. A survey on space vector pulse width modulation technique for a two-level inverter. 2017 National Power Electronics Conference (NPEC). 2017, 78-83.

Lei, T., Barnes M., \& Ozakturk, M. 2013. Doubly-fed induction generator wind turbine modeling for detailed electromagnetic system studies. IET Renewable Energy Generation, 7(2): 180-189.

Li, X., Zhang, X., Lin,Z. \& Niu Y. G. 2018. An Improved Flux Magnitude and Angle Control with LVRT Capability for DFIGs," IEEE Transactions on Power electronics, 33(4): 3845-3853.

Lu, M., Hu, J., Lin, L. \& Xu K. 2017. Zero DC voltage ride through of hybrid modular multilevel converter in HVDC systems. IET Renewable Power Generation, 11(1): 35-43.

Mokhberdoran, A., \& Ajami, A. 2014. Symmetric and asymmetric design and implementation of new cascaded multilevel inverter topology. IEEE Transactions Power Electronics, 29(12): 6712-6724.

Muller, S., Deicke, M. \& Doncker, R. 2002. Doubly fed induction generator systems for wind turbines," IEEE Industrial Applications Magazine, 8(3): 26-33.

Muñoz, J., Rohten, J., Espinoza, J., Melín, P., Baier, C. \& Rivera, M. 2015. Review of current control techniques for a cascaded H-Bridge STATCOM,” IEEE International Conference on Industrial Technology (ICIT). 3085-3090.

Noman, A., Al-Shamma'a, A., Addoweesh, K., Alabduljabbar, A.A. \& Alolah A.I. 2017. A survey on two level and cascaded multilevel inverter topologies for grid connected PV system," IECON 2017 - 43rd Annual Conference of the IEEE Industrial Electronics Society. 2369-2376.

Qiao, W. \& Harle, R. 2008. Grid connection requirements and solutionsfor DFIG wind turbines. In Proc. IEEE Energy 2030 
Conference, Atlanta, GA.1-8.

Rashid, G. \& Ali, M. 2015. Transient stability enhancement of doubly fed induction machine-based wind generator by bridge-type fault current limiter. IEEE Transactions on Energy Conversion, 30(3): 939-947.

Seman, S., Niiranen, J., Kanerva, S., Arkkio, A. \& Saitz, J. 2006. Performance study of a doubly fed wind-power induction generator under network disturbances. IEEE Transactions on Energy Conversion, 21(4): 883-890.

Sebtahmadi, S., Pirasteh, H., Kaboli, S., Radan, A. \& Mekhilef, S. 2015. A 12-Sector Space Vector Switching Scheme for Performance Improvement of Matrix- Converter-Based DTC of IM Drive. IEEE Transactions on Power Electronics, 30(7): 3804-3817.

Sheir, A., Orabi, M., Youssef, M. \& Ahmed M. 2019. Toward a Way to Benchmark Multilevel Inverter Topologies Based on Level to Components Ratio. Canadian Journal of Electrical and computer Engineering, vol. 42, iss. 2, spring 2019.

Tohidi, S., Oraee, H. Zolghadri, M., Shao, S. \& Tavner, P.2013. Analysis and enhancement of low-voltage-ride-through capability of brushless doubly fed induction generator. IEEE Transactions on Industrial Electronics, 60(3): 1146-1155.

Uddin, W., Zeb, K., Tanoli, A. \& Haider, A. 2018. Hardware-based hybrid scheme to improve the fault ride through capability of doubly fed induction generator under symmetrical and asymmetrical fault. IET Generation, Transmission \& Distribution, 12(1): 200-206.

Vidal, J., Abad, G., Arza, J. \& Aurtenechea, S. 2013. Single-phase DC crowbar topologies for low voltage ride through fulfilment of high-power doubly fed induction generator-based wind turbines. IEEE Transactions on Energy Conversion, 28(3): 768-781.

Xiao, X., Yang1, R., Chen, X., Zheng, Z.X. \& Li, C.S. 2018. Enhancing fault ride-through capability of DFIG with modified SMES-FCL and RSC control. IET Generation, Transmission \& Distribution, 12(1): 258-266.

You, Y., Lipo, T. \& Kwon, B. 2012. Optimal design of a grid-connected-to-rotor type doubly fed induction generator for wind turbine systems. IEEE Transactions on Magnetics, 48(11): 3124-2137.

Zhang, L., Zou, Y., Yu, J., Qin J., Vittal V., Karady G.G., Shi D. \& Wang Z. 2017. Modelling, control, and protection of modular multilevel converter-based multi-terminal HVDC systems: A review. Journal of Power and Energy Systems, 23(4): 340-352.

Zou, Z. Chen, X., Li, C., Xiao, X.Y. \& Zhang, Y. 2016. Conceptual design and evaluation of aresistive-type SFCL for efficient fault ride through in a DFIG. IEEE Transactions on Application Super conductivity, 26(1): 560-569.

Zou, X., Zhu, D., Hu, J., Zhou, S., Zhou, S. \& Kang, Y. 2018. Mechanism Analysis of the Required Rotor Current and Voltage for DFIG-based WTs to Ride-Through Severe Symmetrical Grid Faults. IEEE Transactions on Pow electronics, 33(9): 7300-7304. 